\title{
A STUDY ON ANALYTICAL T-STUB PRYING MODELS FOR RHS JOINTS IN TENSION
}

\author{
Andrej MUDROV*, Gintas ŠAUČIUVĖNAS, Antanas ŠAPALAS \\ Department of Steel and Composite Structures, Faculty of Civil Engineering, \\ Vilnius Gediminas Technical University, Sauletekio al. 11, LT-10223, Vilnius, Lithuania
}

Received 3 July 2018; accepted 23 November 2018

\begin{abstract}
The article investigates analytical models for calculation of tension capacity of axially-loaded RHS end-plate joints bolted along two and four sides of the tube in order to investigate the phenomena of prying. Design of such joints is impeded by lack of rules in EN 1993-1-8 and it raises the question whether the Eurocode 3 equivalent T-stub in the tension component should contain integrated assumptions from the AISC/CIDECT/CISC design guides. This paper considers the effect of the bolt hole on the length of the plastic hinge and compares different T-stub models with various assumptions. The behaviour and collapse mechanism of joints with non-preloaded and preloaded bolts was tested during an experiment. The statistical analysis of the test results of 47 joints found in the literature in conjunction with 7 tests determined that it was preferable to use a common approach for connections bolted along two and four sides. Additionally, a limitation of a minimum flange thickness is specified. The performed research has disclosed the benefits and shortcomings of the T-stub models and justified recommendations for their improvement.
\end{abstract}

Keywords: T-stub, flange, bolt, connections, joints, hollow sections.

\section{Introduction}

Rectangular Hollow Section (RHS) end-plate connections in axial tension, due to their symmetry, are a convenient application for exploring the phenomenon of prying forces. The latter occurs in many different types of joints to which T-stub analogy can be applied. Eurocode 3: Design of steel structures 1993-1-8 (European Committee for Standardization, 2005) with its equivalent T-stub in tension model not including any clearly defined rules for calculation of RHS end-plate connections, which leads to different assumptions in designing such joints. A detailed examination of RHS T-stub components demonstrated that the obtained results could be adapted to strength and stiffness analyses of general beam-column joints in bending.

Literature suggests two different cases for calculation of RHS end-plate connections depending on placement of the bolts: along two or four sides of the tube. The first method applies to the modified T-stub end-plate component with a limit on minimum flange thickness. This method was proposed by Packer, Bruno, and Birkemoe (1989) and is provided by the AISC (Packer, Sherman, \& Lecce, 2010), the CISC (Packer \& Henderson, 1997), and the CIDECT (Packer, Wardenier, Zhao, van der Vegte, \&
Kurobane, 2009) design rules. In turn, the connections of the second form, i.e., those bolted along four sides of the tube, are not well established: their method is provided in the AISC rules only. Such joints were explored by Kato and Mukai (1982), Willibald, Packer, and Puthli (2002). Considering the most recent studies on the RHS end-plate connections, it is worth noting the analysis of yield line mechanism and joint stiffness done by Karlsen and Aalberg (2012), the statistical probabilistic assessment of the bearing forces of the end-plate connections by Pišković, Dujmović, and Androić (2014), the design approach suggested by Steige and Weynand (2015), the yield line approach using end-plate tensile strength by Thornton (2017), and the research of steel bolted flange connection in fibre reinforced polymer splice joint by Qiu, Ding, He, Zhang, and Bai (2018).

This study is aimed at examination of the prying phenomena in the axially loaded RHS end-plate connection. The results obtained from the experimental and analytical researches are likely to be used for calculation of the bearing capacity and stiffness of more complex joints affected by bending moments. The paper examines T-stub models

*Corresponding author. E-mail: andrej.mudrov@vgtu.lt 
provided in several design rules, including AISC, CISC, CIDECT, Eurocode 3. The influence of different model assumptions on theoretical joints resistance is compared to the results of seven tests, as well as 47 further tests described in literature. For comparison, additional calculations were made by using semi-empirical STR (The Ministry of Environment of the Republic of Lithuania, 2005) formulas based on the design manual of SP (Ministry of Construction, Housing and Utilities of the Russian Federation, 2017).

\section{Experimental research of the RHS end-plate joints}

Seven specimens bolted along two and four sides of the RHS were tested. This includes four A-series specimens (Figure 1), two of which were bolted along four sides with high-strength preloaded bolts (A1, A2), and the other two were with regular bolts without the initial preload (A3, A4). The last three specimens (C-series) were bolted with high-strength preloaded bolts along two sides (Figure 2).
The average thickness of the end-plate for all specimens equalled to $15.12 \mathrm{~mm}$. The end-plates were welded to the SHS 120x6 tube with a $5 \mathrm{~mm}$ thick fillet weld. Sets of M16, property class 10.9 high-strength bolts meeting standard EN 14399-3:2005 and non-tensioned, M16, property class 10.9 bolts meeting standard EN ISO 4014:2011 were used for connection of the flanges. The set of non-preloaded bolts applied to Style 1 nuts according to standard EN ISO 4032:2013 and washers according to standard EN ISO 7089:2002. The mechanical properties of the coldrolled RHS tube, end-plate steel and high-strength bolts (Table 1) were established from testing in accordance with EN ISO 6892-1:2016.

Preloaded bolts were tightened with a torque wrench to load moment of $280 \mathrm{Nm}$, which corresponds to a tightening load of $110 \mathrm{kN}$. According to EN 1090-2:2008, this tightening load corresponds to $70 \%$ of nominal ultimate bolt strength. Tests of joints were carried out with calibrated $2500 \mathrm{kN}$ power program-controlled tensile strength testing machine at a constant rate of $5 \mathrm{kN} / \mathrm{s}$.

Table 1. The mechanical properties of the materials

\begin{tabular}{|c|c|c|c|c|c|c|}
\hline \multirow{2}{*}{ Index } & \multicolumn{2}{|c|}{ End-plate steel S355J2+N (4 tests) } & \multicolumn{2}{|c|}{ Steel of RHS S355J2H (4 tests) } & \multicolumn{2}{|c|}{ High-strength bolts 10.9 (6 tests) } \\
\hline & Average & St. dev. & Average & St. dev. & Average & St. dev. \\
\hline Yield strength $f_{y}, f_{y b}$ & $407.6 \mathrm{MPa}$ & $4.73 \mathrm{MPa}$ & $496.6 \mathrm{MPa}$ & $15.52 \mathrm{MPa}$ & $1003 \mathrm{MPa}$ & $10.32 \mathrm{MPa}$ \\
\hline Ultimate strength $f_{u}, f_{u b}$ & $570.9 \mathrm{MPa}$ & $5.19 \mathrm{MPa}$ & $544.3 \mathrm{MPa}$ & $15.69 \mathrm{MPa}$ & $1074 \mathrm{MPa}$ & $12.81 \mathrm{MPa}$ \\
\hline Modulus of elasticity $E$ & $256.2 \mathrm{GPa}$ & $13.84 \mathrm{GPa}$ & $277.3 \mathrm{GPa}$ & $32.66 \mathrm{GPa}$ & $229.7 \mathrm{GPa}$ & $16.6 \mathrm{GPa}$ \\
\hline
\end{tabular}

a)
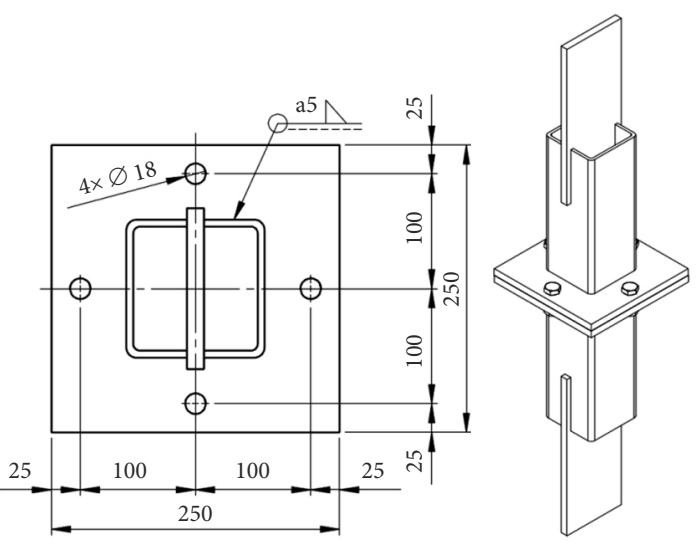

b)

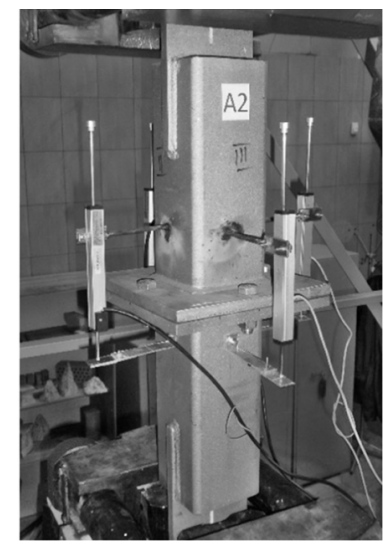

c)

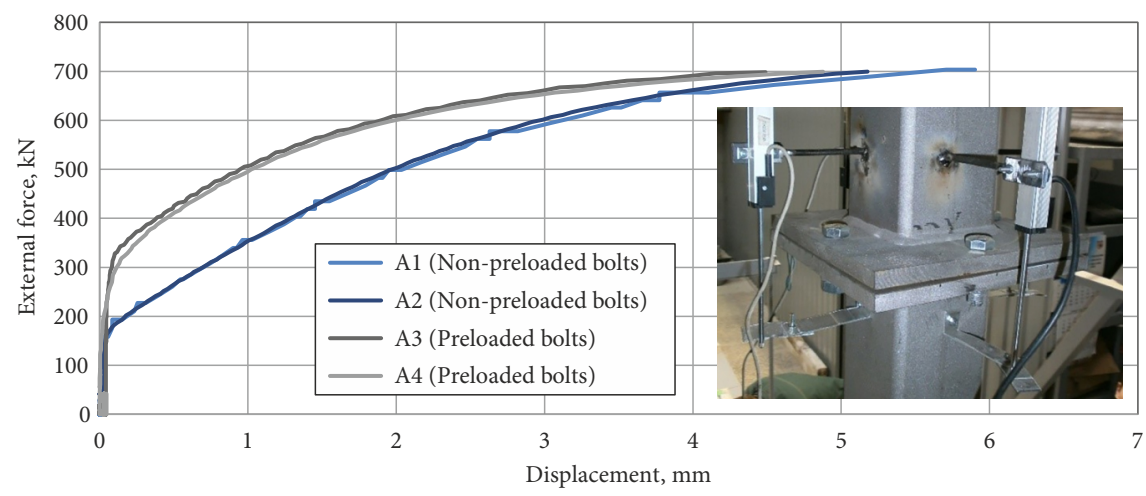

Figure 1. A-series joint: a) joint dimensions; b) test set-up; c) Force-displacement curves for test specimens A1 and A2 with initial bolt preload vs. specimens A3 and A4 with non-preloaded regular bolts 
a)
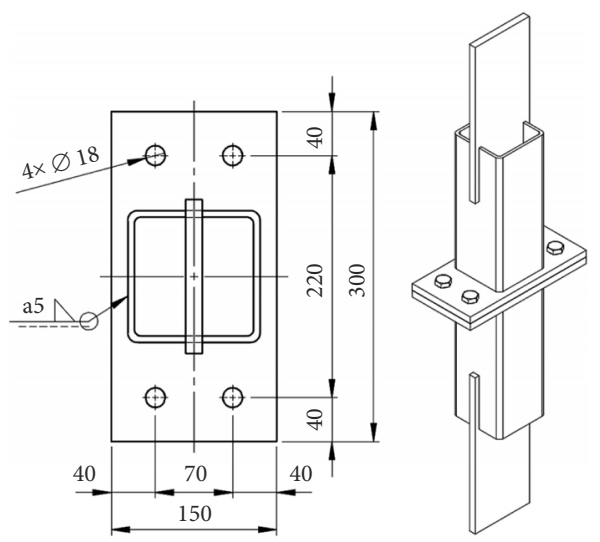

b)
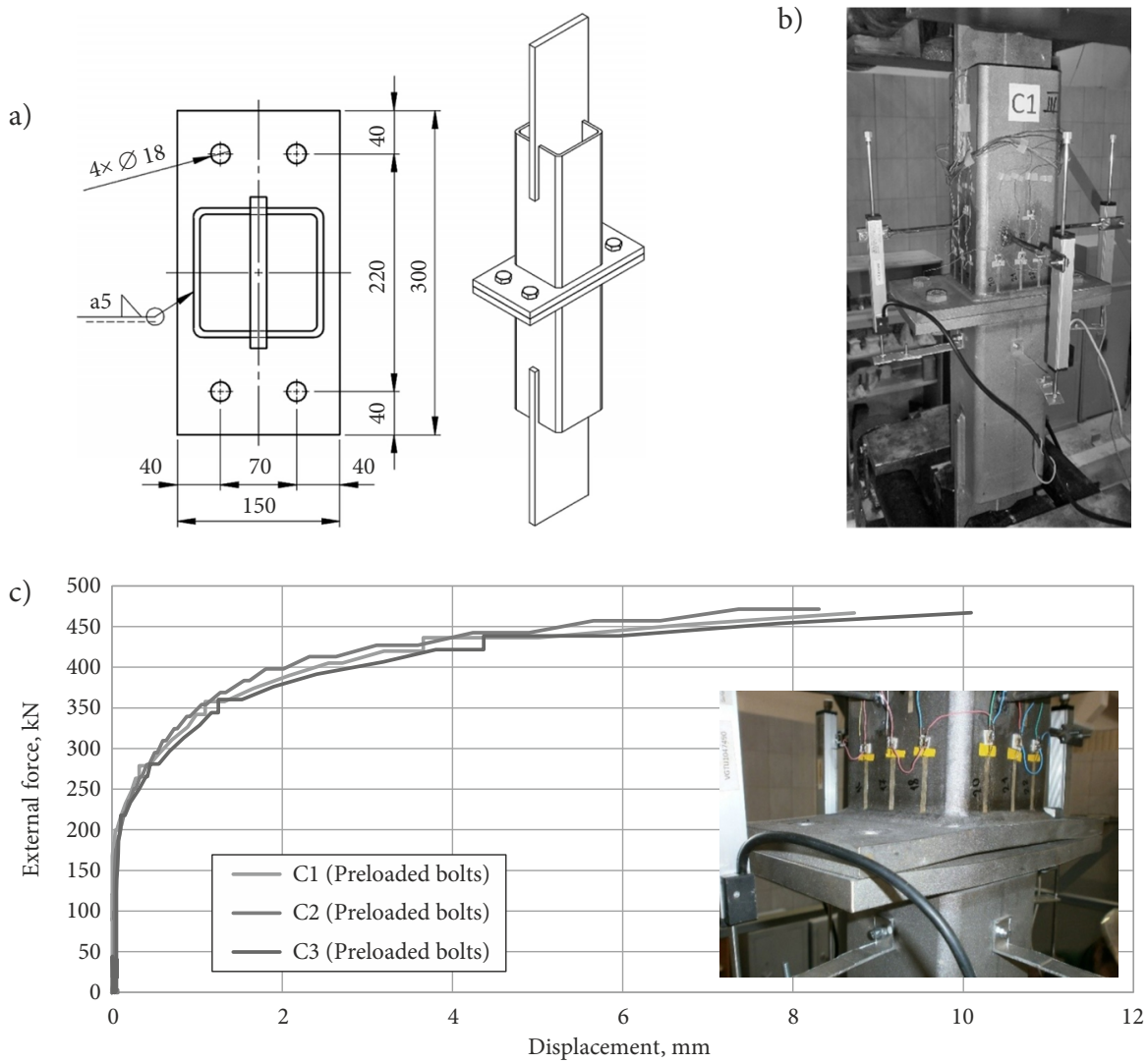

Figure 2. C-series joint: a) joint dimensions; b) test set-up; c) Force-displacement curves for test specimens with initial force preload

In tested joints with preloaded bolts, prying forces are offset by the initial flange clamping and therefore, at the first loading stage, i.e. up to the moment when the gap between the compressed end-plates opens, joint deformations are inconsiderable. This is evidenced by the results of testing the joints with pre-loaded bolts (joint A3, A4 (Figure 1) and all C-series (Figure 2)). Before external force reached $300 \mathrm{kN}$ in A-series and $200 \mathrm{kN}$ in C-series, the displacement of the joint was insignificantly low. The unusually high initial stiffness of the joint with non-preloaded bolts (A1 and A2 (Figure 1)) could be explained by the prior gap between the flanges due to welding deformations. In these joints the bolt thread was visible through a $0.41-\mathrm{mm}$ gap between the end-plates. Consequently, the prying forces could not develop before the edges of the end-plates came in contact. In contrast, there was no prior gap near the bolts in connections with the preloaded bolts, it was only visible at the corners of the end-plates, but it had no effect on them. The average gap at the A3 and A4 joint corners was approximately $1.00 \mathrm{~mm}$. According to LST EN 1090-2, it is considered to be a maximum permitted local gap.

On average, regardless of preloading, A-series connections resisted $700 \mathrm{kN}$. Considering that the stress area of M16 bolt equals to $157 \mathrm{~mm}^{2}$, then the magnitude of stress per bolt had to be $1115 \mathrm{MPa}$, which is $3.7 \%$ higher than the strength established based on testing of high strength bolts (1074 MPa). This suggests that there were no prying forces in the joint. Despite the fact that the joints with

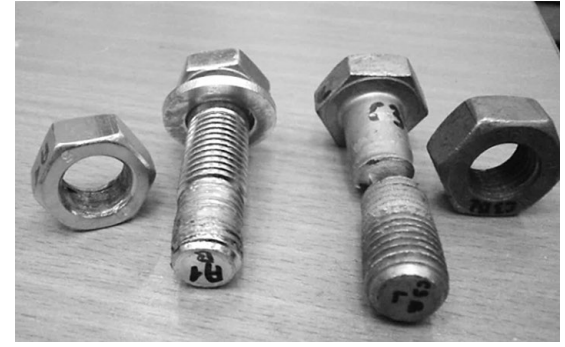

Figure 3. Facture modes of the non-preloaded regular bolts (on the left) and high strength bolts (on the right)

non-preloaded and with preloaded bolts fractured under similar critical forces, characteristics of their fractures were different. High-strength bolts fractured with bolt necking and after testing one could unscrew them easily, while thread stripping was the main failure mode of non-preloaded bolts (Figure 3). The joints bolted along two sides (C-series) also failed when the bolts broke, while their end-plates were bent in double-curvature, which indicates heavy prying forces.

\section{T-stub end-plate component}

In case of EC3 joints, the ultimate load is calculated based on the principle of superposition. In this manner, every joint is simplified by trivial components, such as bolt in shear, weld, etc. As for the end-plate joints, additional prying forces appear in the bolts due to the eccentric bolt po- 
sition and end-plate flexibility. Equivalent T-stub models combining the end-plate and the bolt into a single component are used in order to estimate these forces. In addition to the T-stub, the joint component system includes a weld that is not considered hereunder in this paper. However, it must be noted that, in case of an RHS end-plate joint with bolts on two sides, the effective length of the weld should be calculated in accordance with the AISC manual.

Overall prying phenomenon is a well-studied matter and there are quite a number of models for T-stub endplate components, such as by Douty and McGuire (1965), Nair, Birkemoe, and Munse (1974), Agerskov (1974). The most widely used T-stub model was presented by Struik and de Back (1969) and it even can be found in the AISC and the CIDECT design guides to RHS. A variation of this model was used by Zoetemeijer (1974) for deriving a formula of the effective length for an unstiffened column flange, which was included in Eurocode 3.

The models by Struik and de Back and Zoetemeijer express three limit states: the complete plasticity of the end-plate with the formation of two plastic hinges, bolt fracture under the partial plasticity of the end-plate, and bolt fracture under no plastic deformations of the endplate. Furthermore, these models are unified by an assumption of a rigid plastic material, which is evidenced by the overestimation of prying forces in the case of forming of two plastic hinges (thin end-plate). The main difference amongst these two models lies in determination of the lever of internal forces between the plastic hinges and the resultant force of the bolt.

The model developed by Zoetemeijer accepted uniform pressure distribution under the bolt head in contrast to the model by Struik and de Back where the resultant force of the bolt is moved over half the bolt diameter towards the T-stem, which results in the decreased lever. According to Jaspart and Maquoi (1991), none of these assumptions are in line with experimental observations: Struik's assumption overestimates the local impact of the bolt and Zoetemeijer (Eurocode 3) does not estimate bending of the bolts.

Another possible reason for decreasing the lever is determination of the location of the first plastic hinge near the T-stem. The model by Struik and de Back does not evaluate an increase in flange thickness due to the root radius (filled weld) and therefore the first hinge of this model forms at the stem's face. To the contrary, Zoetemeijer's (Eurocode 3) lever of internal forces is decreased by $0.8 \mathrm{r}$ (where $\mathrm{r}$ is the root radius). However, this decrease is not evident, because, in order to improve accuracy of the original Struik and de Back model, Swanson (2002) recommended decreasing this lever down to 0.5 r. According to Swanson, such reduction produces the highest degree of correlation between the model and experimental results. T-stub model with Swanson's assumption would be referred to as Modified Struik Model.

Another significant improvement in the model for the T-stub end-plate component was proposed by Jaspart and Maquoi (1991). In order to adjust the conservative results of Zoetemeijer's model calculating T-stubs with thin flanges, Jaspart introduced dimension $e$ (which equals to $1 / 4$ of the washer's diameter) into the scheme for Zoetemeijer's model. This allowed dividing the resultant bolt force into two equal vectors (this is a prerequisite), which evaluates the negative impact caused by the washer when, due to its rigidity, the bolt restrains the formation of plastic hinges. This modification greatly improves the accuracy of analytical results in the case of thin end-plates, but it requires equal pressure distribution assumption beneath the bolt head. The Eurocode provides Jaspart's formula as an alternative, which is introduced as the second method.

\section{Application of the T-stub end-plate component for calculation of the RHS end-plate joints}

Packer et al. (1989) analysed the results of testing the RHS joints bolted along two sides which were done by Bruno (1984) and made a conclusion that the standard T-stub models for prediction of the prying forces presented by Struik and de Back (1969), Kulak, Fisher, and Struik (2001), Nair et al. (1974), Douty and McGuire (1965), Kato and McGuire (1972), and Stelco design guide (Stelco, 1981) on hollow structural sections had a poor correlation with the experiments. According to Packer, all of the models listed above, except for Stelco, tend to overestimate the joint strength. The analytical results of Stelco were by $40 \%$ lower in comparison to those of the tests.

The poor congruence of the results may be explained by the specific behaviour of the RHS, which was expressed by Karlsen and Aalberg (2012): depending on position of the bolts along the RHS web and the ratio of the endplate thickness to the thickness of the tube, the part of the end-plate inside the tube may be exposed to considerable bending causing the transverse deformation of tube web, which is most pronounced in the middle parts of the RHS sides. This behaviour was also noted by Packer et al. (1989), they observed that as the deformations of the endplate were increasing, the yielding of end-plate progressed inwards from the weld line towards the centreline of the tube. For this reason, in Packer's model a longer inner lever of internal forces was accepted, the length of which is attributed to the RHS web thickness.

In contrast, for design of RHS joints bolted along four sides, in accordance with the AISC design guide, no changes or restrictions should be taken into the prying model, which mainly contradicts the principle of superposition as the considered joint consists of two mutually perpendicular connections bolted along two sides. This was proven by Willibald et al. (2002). In his study a regular T-stub model without any significant changes is not only in good agreement with experimental results, but it is more precise than that of Packer's with longer inner lever. Unfortunately, the issue of superposition was not considered.

Alternatively, the Lithuanian design rules for steel constructions STR (The Ministry of Environment of the Republic of Lithuania, 2005) provide a T-stub component adopted directly from the SP (Ministry of Construction, 
Housing and Utilities of the Russian Federation, 2017) rules. This model is suitable for both open-type and closed-type profiles in the elastic stage. The joints of the closed-type cross-section must be symmetrical with stiffening plates welded at the corners of the tube, which increases the rigidity of the end-plate. The model limits the maximum permissible distance from the bolts to stiffening plates, thus the RHS connections may only be made with 8 bolts. Furthermore, this model is semi-empirical and suitable for end-plates, the thickness of which makes $83 \%$ of the bolt diameter. Minimal M24 and M27 prestressed bolts are recommended for joints and the surfaces of the end-plates must be milled.

\section{Effective length of the plastic hinge}

The main difficulty in designing connections with different bolt layouts lies in determination of the plastic bending moment, in which the length of the plastic hinge is the main dimension subject to the discretisation. Willibald et al. (2002) distinguishes cases of two-dimensional and three-dimensional yield line patterns of plastic mechanisms. The two-dimensional case of forming plastic hinges is characteristic of the end-plates, which are bolted along two sides. In this case hinges form in the lines parallel to the web of the tube. When the bolts are located along four sides of the RHS, the plastic mechanism becomes threedimensional, which is more complex. The discretization model by Kato and Mukai (1982) may be used as a reference to the three-dimensional fracture mechanism.

With the three-dimensional fracture, the effective length of the plastic hinge is determined by applying the principle of virtual work. This procedure is described in detail by Wang, Zong, and Shi (2013). Alternatively, the AISC HSS Connection Manual offers the analogy of the two-dimensional mechanism, which allows ignoring the principle of virtual work by accepting the length of the plastic hinge as being equal to the width of the tube. Willibald et al. (2002) considered that this assumption was too conservative, and therefore suggested using a greater length related to the width of the end-plate.

The Eurocode provides two models, including the circular one and the non-circular one, as patterns for determination of the effective length of the plastic hinge. In the case of the fracture in two flexible hinges, the effective length of the non-circular model cannot be bigger than that of the circular one. The circular fracture may be considered as an exception, which may be used in the case of stiffening: when the levers of the inner forces are longer than $1.25 \mathrm{~m}$ (Figure $4 \mathrm{a}$ ) or when the bolt is symmetrically loaded (Figure $4 b$ ).

The equations for the Eurocode 3 non-circular model considered below were derived by Zoetemeijer by applying the principle of virtual work to the infinite length zone of the unstiffened column. Zoetemeijer's equation contains two independent unknowns $\alpha$ and $\beta$, i.e., the angles. The size of these angles has an impact on the dimensions of the plastic mechanism (Figure 5), which corresponds to the minimum of potential energy.

In order to formally apply the infinite length assumption, the distance from the bolt hole to the edge of the tube must be no less than "s" (Figure 6):

$$
s \geq 3 m+0.8 n \text {. }
$$
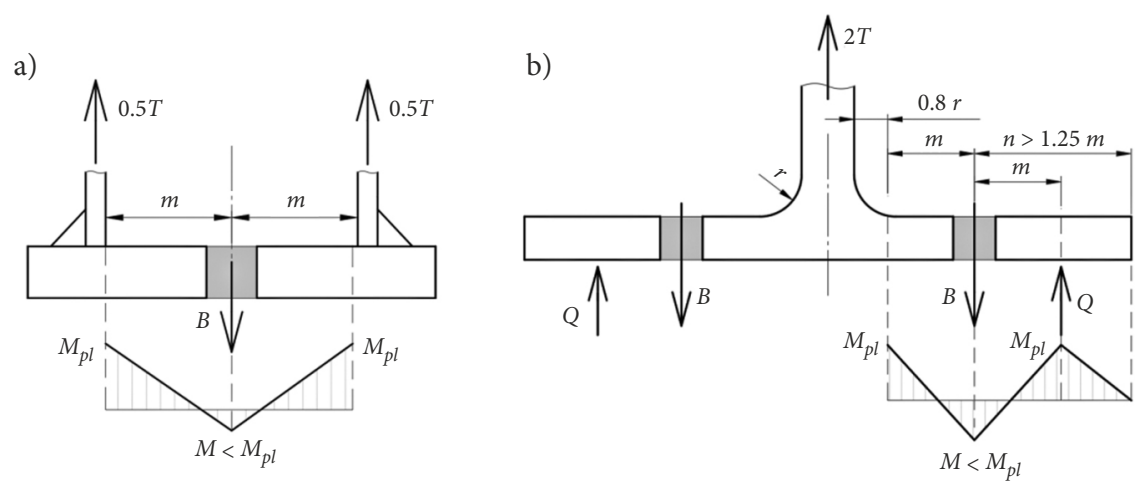

Figure 4. The example of calculated schemes for the circular model: a) structural stiffening; b) stiffening with a long distance to the end-plate's edge
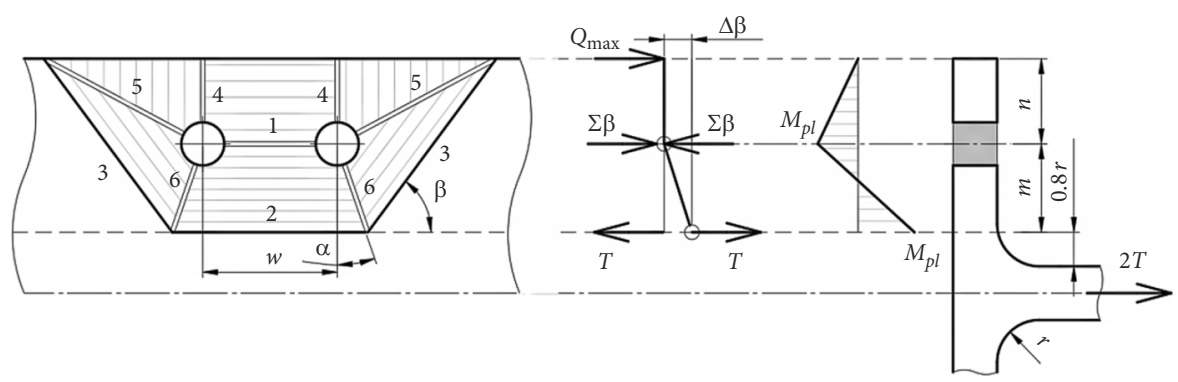

Figure 5. Calculation scheme for Zoetemeijer's mechanism with two-hinges 


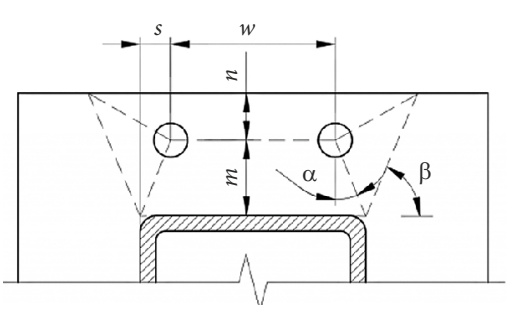

Figure 6. The distance from the bolt to the web of the tube

If the infinite flange assumption is valid, in the case of a single bolt (Figure 1a), the expression of Zoetemeijer's plastic hinge equals to $l_{\text {eff }}=4 m+1.25 n$, and, in the case of the two bolts (Figure 6): $l_{\text {eff }}=2 m+0.625 n+0.5 w$.

These formulas were developed by adopting the significant simplification: the plastic bending moment at the bolt line is equivalent to the plastic moment at the web face (Figure 5). This allows examining only a discrete twohinge mechanism assuming that, in the case of a partial plasticity of the end-plate, the length of the plastic hinge would be twice shorter.

In the original Struik and de Back (1969) model the length of the plastic hinge at the bolt line is reduced due to the net cross-section by multiplying it by magnitude $\delta$. This is a relative value indicating which part of the hinge length is removed by the bolt hole. Analytical calculations show (Figure 7) that the introduction of $\delta$ into the Eurocode's prying model reduces the predicted force and makes it more conservative.

Figure 7 expresses the T-stub design involving verification of three formulas, looking for the smallest result under certain end-plate thickness. The ultimate T-stub force is represented by the curve OAB (Figure 7), the sections of which correspond to a certain fracture: $\mathrm{OA}$ is compatible with the fracture in two hinges, $A B$ agrees with the single-hinged mechanism, and the horizontal dashed line denotes the ultimate bolt strength. If coefficient $\delta$ is applied to the equations for the Eurocode 3 prying model, it decreases curve portion A-B and increases the thin endplate portion $\mathrm{O}-\mathrm{A}$ in which prying forces are overestimated, i.e., the conservatism of the model rises. Also, the figure shows point "E", which is accepted in Packer's model as the minimum allowable thickness of the end-plate. The expressions of this thickness for the prying models with different assumptions are given in Table 2 .

\section{Comparison of analytical and experimental results}

In order to analyse analytic formulas, other tests corresponding to A-series and C-series were taken from literature. Overall, the statistics of 54 tests were collected for the purpose of comparison, including 23 tests by Kato and Mukai (1982), 16 tests by Packer et al. (1989), 4 tests by Willibald et al. (2002), 4 by Karlsen and Aalberg (2012), and 7 tests by Mudrov (2016).

The results of the connections bolted along two sides (C-series) are given in Table 3 and those of the connections bolted on four sides of the tube (A-Series) are provided in Table 4 (were $t_{p}$ is the end-plate thickness, $t_{E}$ is the minimum thickness of the end-plate acc. to Packer). The analytical ultimate forces were calculated without considering partial reliability coefficients. The flanges bolted along the four sides were calculated by using Zoetemeijers plastic hinge length and the connections bolted on two sides were estimated by using the length of the endplate edge. The examined joints do not meet structural requirements of STR (The Ministry of Environment of the Republic of Lithuania, 2005), thus the analytical results obtained under the STR (The Ministry of Environment of the Republic of Lithuania, 2005) model are potentially inappropriate.

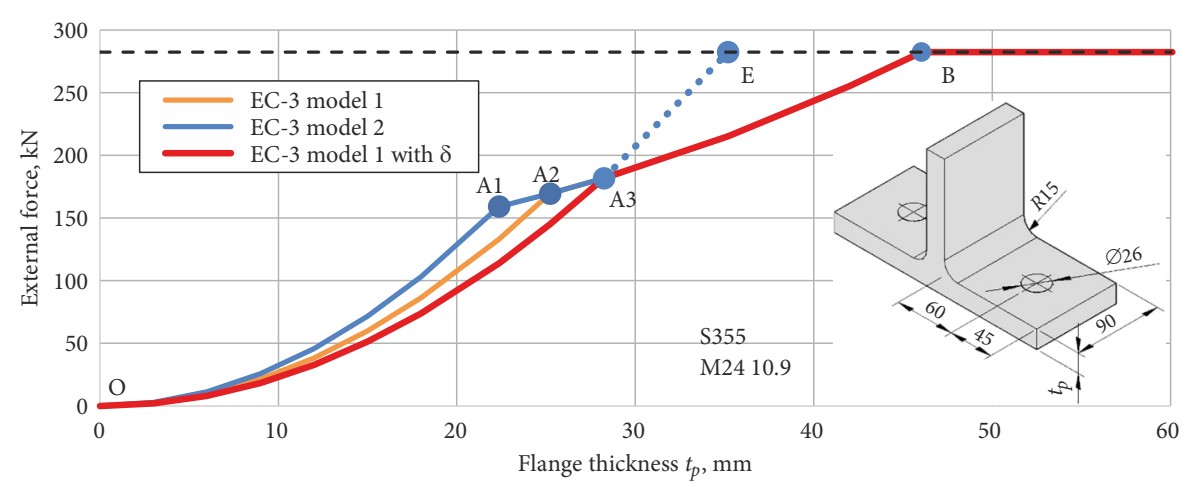

Figure 7. Dependence of the ultimate forces of the T-stub on the flange thickness

Table 2. J. A. Packer's minimum flange thickness for models with different assumptions

\begin{tabular}{|c|c|c|}
\hline J. A. Packer, Struik and de Back & Eurocode Model 1 & Eurocode Model 2 \\
\hline$t_{E}=\sqrt{\frac{4 B_{y d} b^{\prime}}{l_{e f f} f_{y d} \cdot(1+\delta)}}$ & $t_{E}=\sqrt{\frac{2 B_{y d} m}{l_{e f f} f_{y d}}}$ & $t_{E}=\sqrt{\frac{4 B_{y d}(2 m n-e(m+n))}{(4 n-e) l_{e f f} f_{y d}}}$. \\
\hline
\end{tabular}


Table 3. Experimental and theoretical ultimate forces of the end-plate connections bolted along two sides

\begin{tabular}{|c|c|c|c|c|c|c|c|c|c|c|c|c|c|c|c|}
\hline \multirow{2}{*}{\multicolumn{2}{|c|}{ Specimen }} & \multirow{2}{*}{$\begin{array}{c}\text { Actual } \\
\text { strength } \\
F_{u}, \mathrm{kN}\end{array}$} & \multirow{2}{*}{$t_{E} / t_{p}$} & \multicolumn{2}{|c|}{$\begin{array}{c}\text { AISC (1997)/ } \\
\text { Struik }\end{array}$} & \multicolumn{2}{|c|}{$\begin{array}{c}\text { EC3 } \\
\text { (Model 1) }\end{array}$} & \multicolumn{2}{|c|}{$\begin{array}{c}\text { EC3 } \\
\text { (Model 2) }\end{array}$} & \multicolumn{2}{|c|}{ Mod. Struik } & \multicolumn{2}{|c|}{ Packer (1989) } & \multicolumn{2}{|c|}{ STR (2005) } \\
\hline & & & & $F, \mathrm{kN}$ & $F_{u} / F$ & $F, \mathrm{kN}$ & $F_{u} / F$ & $F, \mathrm{kN}$ & $F_{u} / F$ & $F, \mathrm{kN}$ & $F_{u} / F$ & $F, \mathrm{kN}$ & $F_{u} / F$ & $F, \mathrm{kN}$ & $F_{u} / F$ \\
\hline \multicolumn{16}{|c|}{ Packer et al. (1989) } \\
\hline 1 & LB-1 & 443 & 1.07 & 437 & 1.01 & 415 & 1.07 & 415 & 1.07 & 464 & 0.95 & 410 & 1.08 & 251 & 1.76 \\
\hline 2 & LB-2 & 350 & 1.97 & 168 & 2.09 & 190 & 1.84 & 222 & 1.57 & 194 & 1.80 & 145 & 2.41 & - & - \\
\hline 3 & LB-3 & 622 & 1.19 & 653 & 0.95 & 600 & 1.04 & 600 & 1.04 & 694 & 0.90 & 577 & 1.08 & 405 & 1.54 \\
\hline 4 & LB-4 & 793 & 1.31 & 791 & 1.00 & 735 & 1.08 & 735 & 1.08 & 878 & 0.90 & 716 & 1.11 & 515 & 1.54 \\
\hline 5 & LB-5 & 860 & 1.18 & 937 & 0.92 & 841 & 1.02 & 841 & 1.02 & 1004 & 0.86 & 881 & 0.98 & 605 & 1.42 \\
\hline 6 & LB-6 & 955 & 1.02 & 1081 & 0.88 & 983 & 0.97 & 983 & 0.97 & 1171 & 0.82 & 1007 & 0.95 & 717 & 1.33 \\
\hline 7 & LB-7 & 971 & 1.02 & 1091 & 0.89 & 1022 & 0.95 & 1022 & 0.95 & 1176 & 0.83 & 1021 & 0.95 & 717 & 1.35 \\
\hline 8 & LB-8 & 974 & 1.02 & 1091 & 0.89 & 1062 & 0.92 & 1062 & 0.92 & 1176 & 0.83 & 1021 & 0.95 & 717 & 1.36 \\
\hline 9 & LB-9 & 795 & 0.81 & 827 & 0.96 & 772 & 1.03 & 772 & 1.03 & 834 & 0.95 & 771 & 1.03 & 518 & 1.53 \\
\hline 10 & LB-10 & 795 & 0.85 & 810 & 0.98 & 775 & 1.03 & 775 & 1.03 & 840 & 0.95 & 755 & 1.05 & 556 & 1.43 \\
\hline 11 & LB-11 & 1122 & 1.18 & 1413 & 0.79 & 1224 & 0.92 & 1224 & 0.92 & 1530 & 0.73 & 1224 & 0.92 & 870 & 1.29 \\
\hline 12 & LB-12 & 1080 & 1.20 & 1380 & 0.78 & 1194 & 0.90 & 1194 & 0.90 & 1495 & 0.72 & 1163 & 0.93 & 720 & 1.50 \\
\hline 13 & LB-13 & 931 & 1.78 & 622 & 1.50 & 652 & 1.43 & 905 & 1.03 & 786 & 1.18 & 518 & 1.80 & - & - \\
\hline 14 & LB-14 & 490 & 1.69 & 347 & 1.41 & 393 & 1.25 & 492 & 1.00 & 426 & 1.15 & 295 & 1.66 & - & - \\
\hline 15 & LB-15 & 680 & 1.01 & 685 & 0.99 & 643 & 1.06 & 643 & 1.06 & 742 & 0.92 & 638 & 1.07 & 393 & 1.73 \\
\hline 16 & LB-16 & 1164 & 1.18 & 1425 & 0.82 & 1351 & 0.86 & 1351 & 0.86 & 1539 & 0.76 & 1224 & 0.95 & 870 & 1.34 \\
\hline \multicolumn{16}{|c|}{ Mudrov (2016) } \\
\hline 17 & $\mathrm{C} 1$ & 467 & 1.57 & 307 & 1.52 & 349 & 1.34 & 407 & 1.15 & 348 & 1.34 & 269 & 1.74 & 128 & 3.63 \\
\hline 18 & $\mathrm{C} 2$ & 472 & 1.57 & 307 & 1.54 & 349 & 1.35 & 407 & 1.16 & 348 & 1.35 & 269 & 1.76 & 128 & 3.67 \\
\hline 19 & $\mathrm{C} 3$ & 467 & 1.57 & 307 & 1.52 & 349 & 1.34 & 407 & 1.15 & 348 & 1.34 & 269 & 1.74 & 128 & 3.64 \\
\hline \multicolumn{16}{|c|}{ Karlsen and Aalberg (2012) } \\
\hline 20 & A1 & 267 & 2.29 & 112 & 2.38 & 115 & 2.31 & 159 & 1.68 & 127 & 2.09 & 95 & 2,81 & - & - \\
\hline 21 & A2 & 267 & 2.29 & 112 & 2.38 & 115 & 2.31 & 159 & 1.68 & 127 & 2.09 & 95 & 2,81 & - & - \\
\hline 22 & B1 & 267 & 2.06 & 139 & 1.92 & 143 & 1.87 & 196 & 1.36 & 158 & 1.69 & 117 & 2,27 & - & - \\
\hline 23 & $\mathrm{~B} 2$ & 267 & 2.06 & 139 & 1.92 & 143 & 1.87 & 196 & 1.36 & 158 & 1.69 & 117 & 2,27 & - & - \\
\hline \multicolumn{5}{|c|}{ Average: } & 1.307 & & 1.294 & & 1.129 & & 1.167 & & 1.492 & & 1.879 \\
\hline \multicolumn{5}{|c|}{ Standard Deviation: } & 0.520 & & 0.445 & & 0.239 & & 0.433 & & 0.641 & & 0.887 \\
\hline \multicolumn{5}{|c|}{ Minimum: } & 0.782 & & 0.862 & & 0.862 & & 0.722 & & 0.917 & & 1.289 \\
\hline
\end{tabular}

Kato et al. reported that specimens LB-11, LB-12, and LB16 (Table 3) failed by tubes tearing in the HSS (Hollow Square Section) member above the weld and that the bolts had exhibited necking. In specimens S.M20.4.t.12-0.5B $\mathrm{B}_{0}$ and S.M20.4.t.25-0.5B 0 (Table 4) F10T bolts were tightened by a half of the pre-tensile force according to A.I.J. standard (Kato \& Mukai, 1982).

Since Packers model limits the minimum thickness of the end-plates, the ratio of marginal thickness is given next to each specimen in the table of the obtained results (the thinner the flange, the higher the ratio is).

In the case when the thickness limitations are disregarded, the most accurate results, for joints with bolts on two sides, are obtained by employing the second Eurocode 3 method. The most unsafe is the Modified Struik model while the most conservative one is the STR (The Ministry of Environment of the Republic of Lithuania, 2005) model.
The limitation of the flange thickness ratio up to 1.5 should allow significant improvement in analytical results. Thus, in case of Packers model, the average ratio of experimental to theoretical results becomes equal to 1.00 and a standard deviation makes 0.067 . Those of the first and the second methods of the Eurocode 3 make 0.99 and 0.071 and those of the AISC: 0.91 and 0.079 respectively. The average of the Modified Struik model becomes equal to 0.85 with the deviation of 0.082 . The comparison of the models is shown in Figure 8.

Figure 8 clearly shows an increase in conservatism along with decrease in the end-plate thickness. In addition to this, the conventional unsafety of the prying models observed by Packer is confirmed in cases of relatively thick flanges (over $19 \mathrm{~mm}$ ).

As for the connections bolted along four sides (Figure 9), the analytical results obtained by using the modified Struik method were more in line with the tests. 
Having considered 31 samples, the ratio of the marginal thickness of only 5 flanges exceeded 1.5.

In case when these five results are not evaluated, the coefficients of the standard deviation in the results would decrease by $58 \%$ (from 0.161 to 0.068 ) for Mod. Struik and
48\% (from 0.21 to 0.11 ) for the $1^{\text {st }}$ Eurocode 3 method. The average of experimental and theoretical results would also decrease by $5.3 \%$ (from 1.143 to 1.081 ) and by $6.0 \%$ (from 1.274 to 1.197 ) respectively. In case of the $2^{\text {nd }} \mathrm{Eu}$ rocode 3 method, for the AISC and Packer model it would

Table 4. Experimental and theoretical ultimate forces of the flanged connections bolted along four sides

\begin{tabular}{|c|c|c|c|c|c|c|c|c|c|c|c|c|c|c|c|}
\hline \multirow{2}{*}{\multicolumn{2}{|c|}{ Specimen }} & \multirow{2}{*}{$\begin{array}{l}F_{\text {exp }} \\
\mathrm{kN}\end{array}$} & \multirow{2}{*}{$t_{E} / t_{p}$} & \multicolumn{2}{|c|}{$\begin{array}{l}\text { AISC (1997)/ } \\
\text { Struik }\end{array}$} & \multicolumn{2}{|c|}{$\begin{array}{c}\text { EC3 } \\
\text { (Model I ) }\end{array}$} & \multicolumn{2}{|c|}{$\begin{array}{c}\text { EC3 } \\
\text { (Model II ) }\end{array}$} & \multicolumn{2}{|c|}{ Mod. Struik } & \multicolumn{2}{|c|}{ Packer } & \multicolumn{2}{|c|}{ STR/SNiP } \\
\hline & & & & $F, \mathrm{kN}$ & $F_{\exp } / F$ & $F, \mathrm{kN}$ & $F_{\text {exp }} / F$ & $F, \mathrm{kN}$ & $F_{u} / F$ & $F, \mathrm{kN}$ & $F_{u} / F$ & $F, \mathrm{kN}$ & $F_{u} / F$ & $F, \mathrm{kN}$ & $F_{u} / F$ \\
\hline \multicolumn{16}{|c|}{ Willibald et al. (2002) } \\
\hline 1 & $2-7$ & 847 & 1.26 & 694 & 1.22 & 712 & 1.19 & 761 & 1.11 & 771 & 1.10 & 642 & 1.32 & - & - \\
\hline 2 & $2-8$ & 955 & 0.97 & 845 & 1.13 & 828 & 1.15 & 828 & 1.15 & 894 & 1.07 & 796 & 1.20 & 307 & 3.23 \\
\hline 3 & $2-9$ & 792 & 1.30 & 594 & 1.33 & 650 & 1.22 & 694 & 1.14 & 686 & 1.15 & 569 & 1.39 & - & - \\
\hline 4 & $2-10$ & 910 & 0.99 & 801 & 1.14 & 774 & 1.18 & 774 & 1.18 & 845 & 1.08 & 758 & 1.20 & 285 & 3.48 \\
\hline \multicolumn{16}{|c|}{ Kato and Mukai (1982) } \\
\hline 5 & S.M16.4.t.9 & 434 & 1.58 & 383 & 1.13 & 282 & 1.54 & 371 & 1.17 & 311 & 1.39 & 348 & 1.25 & - & - \\
\hline 6 & S.M16.4.t.12 & 562 & 1.23 & 509 & 1.10 & 461 & 1.22 & 472 & 1.19 & 509 & 1.11 & 469 & 1.20 & - & - \\
\hline 7 & S.M16.4.t.16 & 691 & 0.95 & 611 & 1.13 & 577 & 1.20 & 577 & 1.20 & 635 & 1.09 & 575 & 1.20 & 306 & 2.30 \\
\hline 8 & S.M16.4.t.19 & 684 & 0.78 & 669 & 1.02 & 642 & 1.07 & 642 & 1.07 & 684 & 1.00 & 641 & 1.07 & 377 & 1.81 \\
\hline 9 & S.M16.4.t.22 & 664 & 0.69 & 648 & 1.02 & 648 & 1.02 & 648 & 1.02 & 648 & 1.02 & 648 & 1.02 & 425 & 1.53 \\
\hline 10 & S.M20.4.t.9 & 641 & 1.82 & 485 & 1.32 & 331 & 1.94 & 473 & 1.36 & 383 & 1.67 & 431 & 1.49 & - & - \\
\hline 11 & S.M20.4.t.12 & 745 & 1.52 & 675 & 1.10 & 461 & 1.62 & 658 & 1.13 & 533 & 1.40 & 599 & 1.24 & - & - \\
\hline 12 & S.M20.4.t.16 & 951 & 1.16 & 859 & 1.11 & 779 & 1.22 & 779 & 1.22 & 904 & 1.05 & 792 & 1.20 & - & - \\
\hline 13 & S.M20.4.t.19 & 1051 & 0.97 & 931 & 1.13 & 857 & 1.23 & 857 & 1.23 & 972 & 1.08 & 871 & 1.21 & 476 & 2.24 \\
\hline 14 & S.M20.4.t.22 & 1047 & 0.87 & 959 & 1.09 & 891 & 1.18 & 891 & 1.18 & 996 & 1.05 & 905 & 1.16 & 571 & 1.82 \\
\hline 15 & S.M20.4.t.25 & 1045 & 0.75 & 1049 & 1.00 & 1008 & 1.04 & 1008 & 1.04 & 1049 & 1.00 & 1023 & 1.02 & 674 & 1.56 \\
\hline 16 & S.M20.4.t.12-0.5B & 728 & 1.52 & 675 & 1.08 & 461 & 1.58 & 658 & 1.11 & 533 & 1.37 & 599 & 1.21 & - & - \\
\hline 17 & S.M20.4.t.25-0.5B & 1038 & 0.75 & 1049 & 0.99 & 1008 & 1.03 & 1008 & 1.03 & 1049 & 0.99 & 1023 & 1.01 & 674 & 1.56 \\
\hline 18 & L.M20.4.t.12 & 765 & 1.52 & 675 & 1.13 & 455 & 1.68 & 640 & 1.20 & 524 & 1.46 & 599 & 1.28 & - & - \\
\hline 19 & L.M20.4.t.16 & 928 & 1.17 & 856 & 1.08 & 765 & 1.21 & 765 & 1.21 & 894 & 1.04 & 789 & 1.18 & - & - \\
\hline 20 & L.M20.4.t.19 & 1057 & 0.97 & 931 & 1.13 & 848 & 1.25 & 848 & 1.25 & 965 & 1.10 & 871 & 1.21 & 476 & 2.24 \\
\hline 21 & L.M20.4.t.22 & 1052 & 0.87 & 959 & 1.10 & 883 & 1.19 & 883 & 1.19 & 989 & 1.06 & 905 & 1.16 & 571 & 1.82 \\
\hline 22 & L.M20.4.t.25 & 1043 & 0.74 & 1049 & 0.99 & 1018 & 1.02 & 1018 & 1.02 & 1049 & 0.99 & 1040 & 1.00 & 674 & 1.56 \\
\hline 23 & L.M24.4.t.16 & 1167 & 1.37 & 1177 & 0.99 & 791 & 1.47 & 1008 & 1.16 & 964 & 1.21 & 1068 & 1.09 & - & - \\
\hline 24 & L.M24.4.t.19 & 1326 & 1.00 & 1029 & 1.29 & 908 & 1.46 & 908 & 1.46 & 1070 & 1.24 & 954 & 1.39 & - & - \\
\hline 25 & L.M24.4.t.22 & 1481 & 1.04 & 1307 & 1.13 & 1149 & 1.29 & 1149 & 1.29 & 1362 & 1.09 & 1209 & 1.23 & 698 & 2.18 \\
\hline 26 & L.M24.4.t.25 & 1548 & 0.89 & 1456 & 1.06 & 1304 & 1.19 & 1304 & 1.19 & 1507 & 1.03 & 1365 & 1.13 & 870 & 1.80 \\
\hline 27 & L.M24.4.t.28 & 1479 & 0.83 & 1444 & 1.02 & 1306 & 1.13 & 1306 & 1.13 & 1490 & 0.99 & 1363 & 1.09 & 948 & 1.58 \\
\hline \multicolumn{16}{|c|}{ Mudrov (2016) } \\
\hline 28 & $\mathrm{~A} 1$ & 703 & 0.84 & 597 & 1.18 & 562 & 1.25 & 562 & 1.25 & 609 & 1.15 & 580 & 1.21 & 212 & 3.19 \\
\hline 29 & A2 & 699 & 0.84 & 597 & 1.17 & 562 & 1.24 & 562 & 1.24 & 609 & 1.15 & 580 & 1.21 & 212 & 3.19 \\
\hline 30 & A3 & 698 & 0.84 & 597 & 1.17 & 562 & 1.24 & 562 & 1.24 & 609 & 1.15 & 580 & 1.20 & 212 & 3.19 \\
\hline 31 & A4 & 699 & 0.84 & 597 & 1.17 & 562 & 1.24 & 562 & 1.24 & 609 & 1.15 & 580 & 1.21 & 212 & 3.19 \\
\hline \multicolumn{5}{|c|}{ Average: } & 1.119 & & 1.274 & & 1.180 & & 1.143 & & 1.193 & & 2.285 \\
\hline \multicolumn{5}{|c|}{ Standard Deviation: } & 0.089 & & 0.212 & & 0.095 & & 0.161 & & 0.110 & & 0.713 \\
\hline \multicolumn{5}{|c|}{ Minimum: } & 0.989 & & 1.024 & & 1.024 & & 0.989 & & 1.003 & & 1.527 \\
\hline
\end{tabular}




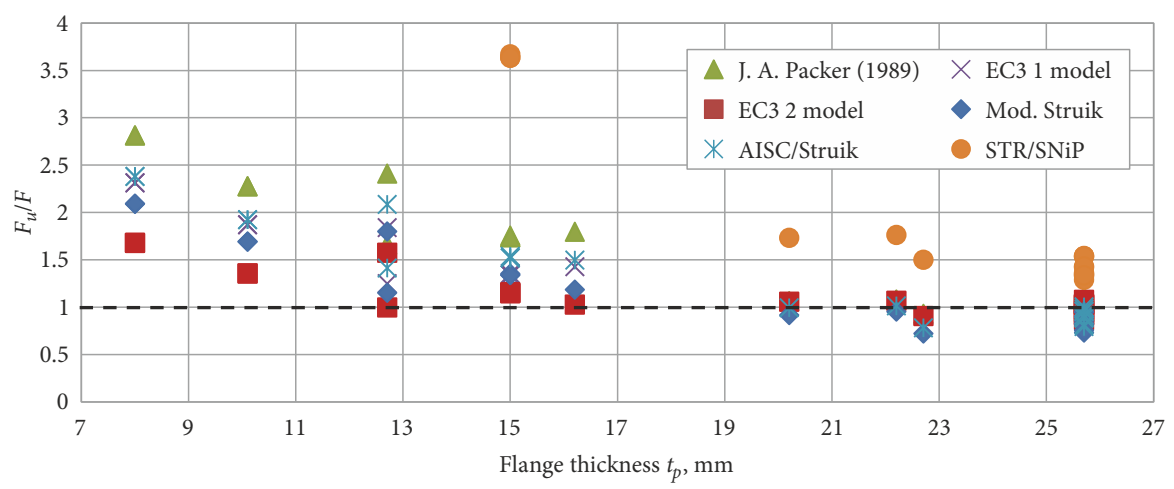

Figure 8. Comparison of the selected models considering the flanged connections bolted along two sides

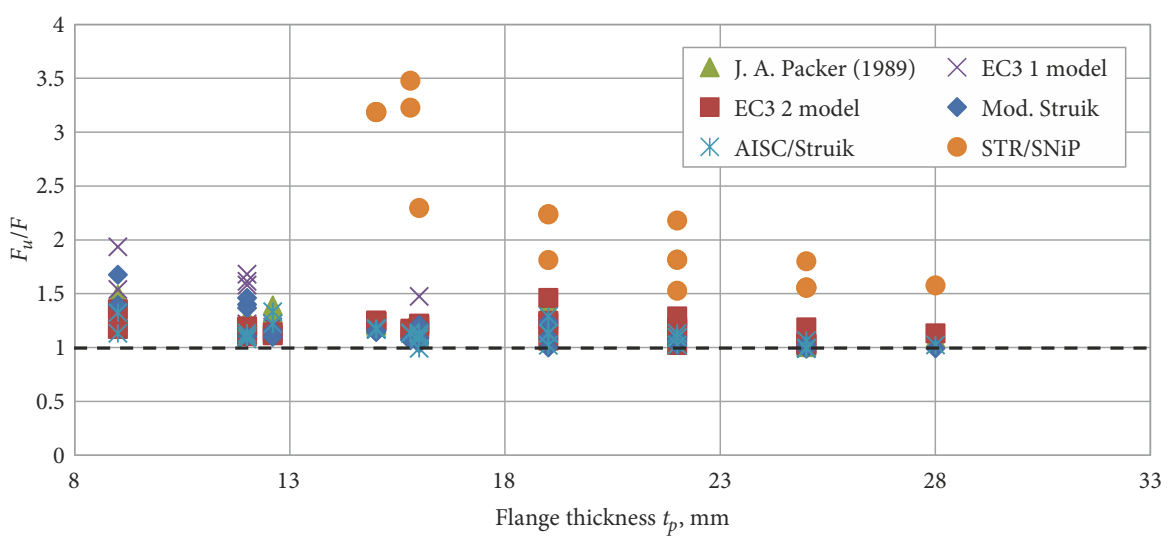

Figure 9. Comparison of the selected models considering the flanged connections bolted along four sides

not make any significant difference: it would slightly increase deviation of the Eurocode 3 by $1.3 \%$ and decrease deviations of the AISC model by $1.3 \%$ and Packer's by $8.4 \%$.

\section{Conclusions}

1. The superposition principle of the T-stub is valid regardless of the selected levers of internal forces. Thus, even calculations, including Packers plastic hinge mechanism, point to overestimation the ultimate force up to $8.3 \%$. Hence, the use of different assumptions for end-plate connections bolted along two sides and along four sides of the tube is not required.

2. The equations based on the model developed by Struik and de Back overestimate the impact of prying forces in case of the two-hinged mechanism and therefore the limitation of the minimum thickness of the end-plate might provide significant assistance in improving accuracy of the models. Approximately this may be done by limiting the minimum thickness to $2 / 3$ of $t_{E}$. As for the practical calculations, such limitations may be ignored: in case of thin flanges, the analytical results would have a higher safety margin.

3. Net cross-sectional estimation due to the bolt hole suggests more conservative results. On the contrary, the modified Struik's model leads to overestimation of the ultimate force.

4. Joints with preloaded high-strength and nonpreloaded regular bolts sustain the same ultimate force in tension regardless of the bolts' failure mode (high-strength bolts fracture with bolt necking, whereas the non-preloaded regular ones fail by thread stripping). The initial tightening of the bolt has no effect on the maximum load of the joint. Stiffness of the joint depends on the initial pretension of the bolts and the prying forces. Development of the prying forces depends not only on the initial clamping force but also on the initial imperfections of the end-plates.

\section{References}

Agerskov, H. (1974). Behaviour of connections using prestressed high strength bolts loaded in tension (Report No. R55). Department of Structural Engineering, Technical University of Denmark, Lyngby, Denmark.

Bruno, L. (1984). Bolted end-plate splices in HSS tension members (Masters thesis). University of Toronto, Toronto, Ontario, Canada.

Douty, R. T., \& McGuire, W. (1965). High strength moment connections. Journal of Structural Engineering, 91(4), 101-128.

European Committee for Standardization. (2005). Eurocode 3: Design of steel structures. Part 1-8: Design of joints (EN 19931-8:2005). Brussels, Belgium. 
Jaspart, J. P., \& Maquoi, R. (1991). Plastic capacity of end-plate and flange cleated connections- predictions and design rules. Paper presented at the Proceedings of the 2nd International Workshop on Connections in Steel Structures: Behaviour, Strength, and Design, 10-12 April. Pittsburgh, USA.

Karlsen, F. T., \& Aalberg, A. (2012). Bolted RHS end-plate joints in axial tension. Paper presented at the Proceedings of the Nordic Steel Construction Conference, 5-7 September, Oslo, Norway.

Kato, B., \& Mukai, A. (1982). Bolted tension flanges joining square hollow section members (CIDECT Rep. 8B-82/3 E). University of Tokyo, Tokyo, Japan.

Kato, B., \& McGuire, W. (1972). Analysis of T-stub flange connections. Journal of Structural Engineering, 99(5), 865-888.

Kulak, G. L., Fisher, J. W., \& Struik, J. H. A. (2001). Guide to design criteria for bolted and riveted joint (2nd ed.). American Institute of Steel Construction.

Ministry of Construction, Housing and Utilities of the Russian Federation. (2017). SNiP II-23-81* Steel structures (SP 16.13330.2017). Retrieved from https://docs.cntd.ru/ document/1200084089

Mudrov, A. (2016). Study of flange-plate connections and behaviour of bolts in tension (Master thesis). Vilnius Gediminas Technical University (in Lithuanian).

Nair, R. S., Birkemoe, P. C., \& Munse, W. H. (1974). High strength bolts subject to tension and prying. Journal of the Structural Division, American Society of Civil Engineers, 100(2), 351-372.

Packer, J. A., Bruno, L., \& Birkemoe, P. C. (1989). Limit analysis of bolted RHS flange plate joints. Journal of Structural Engineering, 115(9), 2226-2242.

https://doi.org/10.1061/(ASCE)0733-9445(1989)115:9(2226)

Packer, J. A., \& Henderson, J. E. (1997). Hollow structural section connections and trusses - A design guide (2nd ed.). Canadian Institute of Steel Construction, Toronto, Canada.

Packer, J. A., Sherman, D., \& Lecce, M. (2010). Hollow structural section connections: Steel design guide No 24. American Institute of Steel Construction. Chicago, USA.

Packer, J. A., Wardenier, J., Zhao X.-L., van der Vegte, G. J., \& Kurobane, Y. (2009). Design guide for rectangular hollow section (RHS) joints under predominantly static loading (2nd ed.). Geneva, Switzerland: CIDECT.

Pišković, J., Dujmović, D., \& Androić, B. (2014). Probabilistic analysis of bolted RHS end-plate joints in axial tension. Paper presented at the EUROSTEEL 2014, 7th European Conference on Steel and Composite Structures. Naples, Italy: ECCS European Convention for Constructional Steelwork.

Qiu, C., Ding, C., He, X., Zhang, L., \& Bai, Y. (2018). Axial performance of steel splice connection for tubular FRP column members. Composite Structures, 189, 498-509.

https://doi.org/10.1016/j.compstruct.2018.01.100

Steige, Y., \& Weynand, K. (2015). Design resistance of end plate splices with hollow sections. Steel Construction, 8(3), 187-193. https://doi.org/10.1002/stco.201510023

Stelco, Inc. (1981). Hollow structural sections - design manual for connections (2nd ed.). Hamilton, Ontario, Canada.

Struik, J. H. A., \& de Back, J. (1969). Tests on bolted T-stubs with respect to a bolted beam-to-column connection (Stevin Laboratory Rep. 6-69-13). Delft University of Technology, Delft, The Netherlands.

Swanson, J. A. (2002). Ultimate strength prying models for bolted T-stub connections. Engineering Journal, 39(3), 136-147.

The Ministry of Environment of the Republic of Lithuania. (2005). Technical regulations of building construction. Design of steel structures. General attitudes (STR 2.05.08:2005). Vilnius, Lithuania.
Thornton, W. A. (2017). Yield Line Approaches for design of end plate tension connections for square and rectangular HSS members using end plate tensile strength. American Institute of Steel Construction, 54, 141-154.

Wang, Y. Q., Zong, L., \& Shi, Y. J. (2013). Bending behaviour and design model of bolted flange-plate connection. Journal of Constructional Steel Research, 84, 1-16. https://doi.org/10.1016/j.jcsr.2013.01.012

Willibald, S., Packer, A. J., \& Puthli, S. R. (2002). Experimental study of bolted HSS flange-plate connections in axial tension. Journal of Structural Engineering, 128(3), 328-336. https://doi.org/10.1061/(ASCE)0733-9445(2002)128:3(328)

Zoetemeijer, P. (1974). A design method for the tension side of statically loaded, bolted beam-to-column connections. Stevin Laboratory, Delft University of Technology, Delft, the Netherlands. 